\title{
¿Autoridad emancipatoria? Una aproximación desde El maestro ignorante de Jacques Rancière*
}

\author{
Lautaro Steimbreger ${ }^{* *}$
}

Recibido: 13 de marzo de 2018 - Aprobado: 11 de julio de 2018

\section{Resumen}

Autoridad y emancipación son dos nociones que en principio se nos presentan como opuestas. Mientras que la primera presupone una disimetría, la igualdad es inherente a la segunda; mientras que obediencia y sumisión se emparentan con la primera, libertad es un sinónimo de la segunda. Pero, ¿es posible hallar puntos de encuentro entre los vínculos de autoridad en el campo educativo y la emancipación intelectual de los individuos?, ¿existe una tal autoridad emancipatoria? En el presente artículo, abordamos este problema retomando la historia del pedagogo francés del siglo XIX Joseph Jacotot y la lectura que hace de ella el filósofo Jacques Rancière en su obra El maestro ignorante. Iniciamos el recorrido con un rastreo conceptual de las nociones en cuestión para identificar rasgos y elementos propios de cada una sin desatender a las paradojas que ambas traen consigo. La autoridad admitirá distintas figuras o manifestaciones, que van de la ceñida relación mando/obediencia a la generatividad del auctor. La emancipación será definida por el principio de igualdad de inteligencias y la hipótesis de confianza. Posteriormente, sostenemos que Jacotot ofició como una figura de autoridad, primero, por el tipo de relación pedagógica que sostuvo con los estudiantes de la Universidad de Lovaina, y segundo, porque en su camino produjo libros, fundó un método de enseñanza, creó un periódico y cosechó discípulos. Así, veremos que en su persona convergen no solo los fenómenos de autoridad y emancipación, sino también las distintas formas en las que la autoridad se manifiesta.

Palabras clave: autoridad, emancipación, relación pedagógica, Jacotot, Rancière.

* Artículo de reflexión. Elaborado en el marco de la beca doctoral otorgada por el Consejo Nacional de Investigaciones Científicas y Técnicas (Conicet), Argentina. Citar como Steimbreger, L. (2019). ¿Autoridad emancipatoria? Una aproximación desde El maestro ignorante de Jacques Rancière. Análisis, 51(94), 57-79. DOI: https://doi.org/10.15332/10.15332/ s0120-8454.2019.0094.03

** Psicólogo por la Universidad Nacional del Comahue (Unco), Patagonia argentina. Docente investigador de la Facultad de Ciencias de la Educación de la Unco. Estudiante del Doctorado en Educación de la misma institución. Becario doctoral del Instituto Patagónico de Estudios de Humanidades y Ciencias Sociales (IPEHCS), Conicet-Unco, Argentina. Dirección postal: Buenos Aires 1400, Neuquén, Argentina. Correo electrónico: lautarosteimbreger@gmail.com. Orcid: https://orcid. org/0000-0002-6286-3536 


\section{Emancipatory authority? An approach from The ignorant schoolmaster of Jacques Rancière*}

Lautaro Steimbreger*

Authority and emancipation are two notions that, at first sight, appear to us as opposites. While the first presupposes a dissymmetry, equality is inherent to the second; while obedience and submission are related to the first, freedom is a synonym of the second. But is it possible to find points of contact between the links of authority in the field of education and the intellectual emancipation of individuals? Or is there such an emancipatory authority? In this article, we face this problem by recapturing the history of a nineteenth-century French pedagogue, Joseph Jacotot, and the reading that the philosopher Jacques Rancière makes of it in his work The ignorant schoolmaster. We begin the journey with a conceptual tracing of the notions in question in order to identify features and elements of each one, without neglecting the paradoxes that both bring with them. The authority will admit different figures or manifestations that go from the tight relation command/obedience, to the generativity of the auctor. Emancipation will be defined by the principle of equality of intelligences and the hypothesis of trust. Subsequently, we maintain that Jacotot officiated as a figure of authority, first, by the type of pedagogical relationship he held with the students of the University of Louvain, and second, because in his path he produced books, founded a teaching method, created a newspaper and reaped disciples. Thus, in him converge not only the phenomena of authority and emancipation, but also the different ways in which authority manifests itself.

Keywords: authority, emancipation, pedagogical relationship, Jacotot, Rancière

* Reflection article. Elaborated in the framework of the doctoral grant conceded by the National Council of Scientific and Technical Research (Conicet), Argentina. Quote as Steimbreger, L. (2019). ¿Autoridad emancipatoria? Una aproximación desde El maestro ignorante de Jacques Rancière. Análisis, 51(94), 57-79. DOI: https://doi.org/10.15332/10.15332/ s0120-8454.2019.0094.03

** Psychologist by the National University of Comahue (Unco), Argentine Patagonia. Research professor at the Faculty of Educational Sciences of Unco. Student of the Doctorate in Education of the same institution. PhD scholar of the Patagonian Institute of Humanities and Social Sciences Studies (IPEHCS), Conicet-Unco, Argentina. Mailing address: Buenos Aires 1400, Neuquén, Argentina. E-mail: lautarosteimbreger@gmail.com. Orcid: https://orcid.org/0000-0002-6286-3536 


\title{
Autorité émancipatoire? Une réflexion à propos du Maître ignorant de Jacques Rancière*
}

\author{
Lautaro Steimbreger**
}

\section{Résumé}

Autorité et émancipation sont deux notions qui, en principe, nous sont présentées comme étant opposées. Si la premières d'entre elles suppose une dissymétrie, l'égalité est inhérente à la deuxième. L'obéissance et la soumission s'apparentent à l'autorité, la liberté est synonyme de l'émancipation. Or, est-il possible trouver des points communs entre les liens d'autorité au sein de l'éducation et l'émancipation intellectuel des individus ? Cet article revient sur cette question en faisant appel à l'histoire du pédagogue français Joseph Jacotot, et à la lecture qui en fait Jacques Rancière dans Le Maître ignorant. On commence avec une quête des notions en question pour y identifier des traits et des éléments propres à chacune sans négliger les paradoxes qu'elles incarnent. L'autorité admet des figures différentes, qui vont de la relation mandat/obéissance à la générativité de l'auctor. L'émancipation, quant à elle, est définie par le principe de l'égalité des intelligences et l'hypothèse de la confiance.

Puis nous affirmons que Jacotot a officié comme une figure d'autorité, d'abord, par la relation qu'il a créée avec les étudiants de l’Université de Louvain et, ensuite, parce qu'il a produit des livres, a fondé une méthode d'enseignement, a fait un journal et a fédéré des disciples autour de lui. Dans sa personne convergent donc l'autorité et l'émancipation mais aussi les formes différentes que l'autorité peut assumer.

Mots clés: autorité, émancipation, relation pédagogique, Jacotot, Rancière.

Article de réflexion produit dans le cadre d'une bourse de doctorat accordée par le Conseil Nationale de Recherches Scientifiques et Techniques (Conicet), Argentine. Pour citation: Steimbreger, L. (2019). ¿Autoridad emancipatoria? Una aproximación desde El maestro ignorante de Jacques Rancière. Análisis, 51(94), 57-79. DOI: https://doi. org/10.15332/10.15332/s0120-8454.2019.0094.03

** Psychologue de l'Université Nationale de Comahue (Unco), Patagonie argentine. Professeur et chercheur à la Faculté de Sciences de l'Éducation de la Unco, où il fait un doctorat en Éducation. Boursier doctoral à l'Institut Patagonique d'Études en Humanités et Sciencies Sociales (IPEHCS), Conicet-Unco, Argentine. Adresse postale: Buenos Aires 1400, Neuquén, Argentina. Adresse électronique: lautarosteimbreger@gmail.com. Orcid: https://orcid.org/0000-0002-6286-3536 


\section{Una historia conocida}

En 1818, el pedagogo francés Joseph Jacotot se vio en la necesidad de resolver una situación educativa problemática: ¿cómo enseñar francés a un grupo de estudiantes de la Universidad de Lovaina, Bélgica, sin saber hablar ni comprender su idioma, el holandés? No había receta alguna para ello, tuvo que improvisar. La solución de compromiso fue hacerles llegar la edición bilingüe de Telémaco, de Fenelón, y pedirles que aprendieran el francés ayudados con la traducción. Solo eso, un libro, una consigna y esperar a ver qué ocurre. $\mathrm{Al}$ poco tiempo advirtió -no sin sorpresa- que los estudiantes, sin su ayuda y sus explicaciones, algo habían aprendido: lograron hacer uso del francés para contar lo que habían leído. Con este hecho accidental Jacotot constató que se puede aprender sin las explicaciones del maestro y que este puede ignorar aquello que pretende enseñar. Los acontecimientos iban a contrapelo de las grandes corrientes pedagógicas de la época, para las cuales la tarea del maestro consistía en la transmisión gradual de los conocimientos que él detenta a los estudiantes. Desde esta perspectiva la explicación resultaba un recurso imprescindible. No conforme con esta constatación y el revuelo ocasionado en el ámbito académico, el pedagogo se propuso repetir eso que había logrado por azar, y en 1823 publica su primer libro, Enseñanza universal. Lengua materna, donde reúne una serie de lecciones, ejercicios, reflexiones, discusiones y principios que darán forma a su nuevo método de enseñanza.

Será el filósofo franco-argelino Jacques Rancière el que va a resucitar y revitalizar a finales del siglo XX la figura de Joseph Jacotot para poner en tensión algunos debates político-pedagógicos que se estaban dando en Francia en aquella época. El libro El maestro ignorante. Cinco lecciones para la emancipación intelectual, publicado en Francia en 1987, es la materialización de su propia lectura de los hechos históricos y de las obras que Jacotot dejó a disposición.

Ahora bien, ¿qué sentido tiene resucitar esta vieja historia en las discusiones pedagógicas de esta primera mitad del siglo XXI? En el "Prólogo" que Rancière realiza para su libro se hace una pregunta similar y se sugiere una respuesta: es necesario volver a oír la disonancia propia de la institución pedagógica que Jacotot hizo escuchar "para que el acto de enseñar no pierda nunca por completo la conciencia de las paradojas que le dan sentido" (Rancière, 2007, pp. 7 - 8).

Creemos que la experiencia de Jacotot y la lectura que hace de ella Rancière pueden resultar una potente herramienta para pensar y producir nuevos sentidos sobre eso que hacemos en tanto educadores y sobre aquello que de un modo $\mathrm{u}$ otro anhelamos para el presente y el futuro de los sujetos a quienes dirigimos nuestros actos de enseñanza. En este terreno, la emancipación intelectual se presenta como un horizonte ético y político para orientar nuestras miradas y acciones en el contexto educativo y para habitar la relación pedagógica en clave de igualdad. 
Con el presente escrito nos proponemos hacer una lectura de la noción de autoridad a partir de los principios de la enseñanza universal fundada por Jacotot y revitalizada por Rancière. Más específicamente perseguimos el propósito de hallar puntos de encuentro entre autoridad y emancipación intelectual. Iniciar una búsqueda tal quizá nos permita arribar a algunos sentidos del acto de enseñar, esos que precisan de nuestra atención para andar y desandar las paradojas. La pregunta que orientará nuestro recorrido es: ¿Qué puntos de encuentro se pueden hallar entre los vínculos de autoridad en el campo educativo y la emancipación intelectual de los individuos? O expresada de otro modo, ¿existe una tal autoridad emancipatoria?

\section{Planteamiento de un problema}

En principio, los términos autoridad y emancipación se nos presentan como opuestos o contradictorios. Mientras que el primero presupone una cierta disimetría, el segundo solamente puede concebirse en términos de igualdad. Mientras que obediencia y sumisión son actos implicados en los vínculos de autoridad, libertad suele usarse como sinónimo de emancipación. Por un lado, es difícil concebir institución social alguna sin la presencia de determinadas figuras de autoridad; por otro, la igualdad de inteligencias y la emancipación huyen de lo instituido y del orden social en todas sus formas. Según Rancière (2007), las instituciones pedagógicas son
el lugar -material y simbólico- donde el ejercicio de la autori- dad y la sumisión de los sujetos no tiene otro objetivo que el de la progresión de esos sujetos hasta alcanzar el límite de su capacidad: el conocimiento de las materias del programa para la mayoría; la capacidad de convertirse, llegado el momento, en maestros, para los mejores. (p. 8)

En esta expresión autoridad e institución pedagógica quedan ligadas y a la vez relegadas al terreno del embrutecimiento y la desigualdad. La autoridad que ejerce el maestro oficia como techo para la capacidad del estudiante, quien únicamente podrá contentarse con llegar a conocer aquello que su maestro ofrece progresivamente.

Hasta aquí todo dice que autoridad y emancipación se encuentran en veredas opuestas y que el intento por conjugar ambos términos no puede prescindir de la negación de uno de ellos. En este sentido, una tal autoridad emancipatoria sería un oxímoron o una paradoja radical. Pero insistiremos en nuestra exploración: aun así, ¿es posible hallar puntos de encuentro entre autoridad y emancipación? $\mathrm{O}$ ¿qué tipo de vínculo de autoridad puede acoger la igualdad de inteligencias?

Si nos proponemos seguir los principales postulados de la enseñanza universal, la cita de Rancière resulta inobjetable. Sin embargo, podemos revisar el uso que se hace allí del término autoridad. Por ello, en principio, identificaremos 
determinados rasgos y elementos propios de la autoridad a partir de las pistas que ofrecen algunos autores. Luego desarrollaremos la noción de emancipación desde la perspectiva de Jacotot y Rancière. Y por último acudiremos a la propia experiencia de Jacotot para explorar allí intersecciones posibles entre ambos fenómenos.

\section{¿Qué autoridad?}

La tarea de ofrecer una definición más o menos ajustada de lo que la autoridad es en la actualidad, presenta sus propias dificultades. Según el uso que se haga de este término su significado fluctúa entre polos opuestos: hay quienes la juzgan déspota de otros tiempos y quienes reclaman su reivindicación, quienes temen su peso y quienes reprochan su liviandad, quienes declaran su declive y quienes constatan su multiplicación. La etimología de la palabra ofrece algunas coordenadas para definirla: autoridad (del latín, auctoritas) deriva augere, que significa "aumentar", "promover", "acrecentar", "incrementar". No obstante, su discurrir semántico ha derivado en figuras diversas, que se acercan o se alejan de esta raíz. Y con estas variaciones también se diversificaron las experiencias con la autoridad. Esto último, fue advertido por Arendt (1996) a mediados del siglo XX: "La autoridad se ha esfumado del mundo moderno. En vista de que no podemos ya apoyarnos en experiencias auténtica e indiscutiblemente comunes a todos, la propia palabra está ensombrecida por la controversia y la confusión" (p. 101). Una sombra que parece extenderse hasta la actualidad.

La autoridad que para Arendt se esfumó es la que prevaleció durante largo tiempo en el mundo occidental; aquella que, sostenida por las fuerzas de la tradición y la religión, era asumida como un imperativo natural que servía de modelo para diferentes formas de gobierno autoritario. Dicha autoridad comenzaba a mostrar sus fisuras y peligros, al punto de perder su carácter admisible. En su ensayo de 1954, bajo el título ¿Qué es la autoridad?, la filósofa alemana se remonta a la historia política de la antigua Roma, cuna de la auctoritas, para ofrecer algunos rasgos característicos de este fenómeno que atañe a la convivencia humana:

La autoridad siempre demanda obediencia y por ese motivo es corriente que se la confunda con cierta forma de poder o de violencia. No obstante, excluye el uso de medios externos de coacción: se usa la fuerza cuando la autoridad fracasa. Por otra parte, autoridad y persuasión son incompatibles, porque la segunda presupone la igualdad y opera a través de un proceso de argumentación. Cuando se utilizan los argumentos, la autoridad permanece en situación latente. Ante el orden igualitario de la persuasión se alza el orden autoritario, que siempre es jerárquico. Si hay que definirla, la autoridad se diferencia tanto de la coacción por la fuerza como de la persuasión por argumentos (la relación autoritaria entre el que manda y el que obedece no se apoya en una razón común ni en el poder del primero; lo que tienen en común es la jerarquía 
misma, cuya pertinencia y legitimidad reconocen ambos y en la que ambos ocupan un puesto predefinido y estable). (Arendt, 1996, pp. 102-103)

Se trata, entonces, de un modo de relación humana del tipo mando/obediencia, que se distancia tanto del orden de la igualdad como del orden del poder entendido en términos de dominación por coacción. Al descartar el uso de la fuerza, lo que entra en escena en dicha relación es un componente volitivo por parte de quien obedece: a fin de cuentas lo hace porque quiere. En otra ocasión Arendt (1996, p. 116) afirma: "La autoridad implica una obediencia en la que los hombres conservan su libertad". De este modo, la autoridad se aleja por completo de determinadas experiencias políticas signadas por la opresión, la tiranía, el absolutismo o la dominación, formas de gobierno autoritario que menoscaban las libertades de quienes yacen bajo su yugo. Por último, otro componente que encontramos en la extensa cita de Arendt es el reconocimiento: los implicados en esta relación reconocen la pertinencia y legitimidad de la jerarquía que los ubica en un orden a partir de puestos previamente establecidos y bien diferenciados.

Revault d'Allonnes sigue atentamente el recorrido iniciado por Arendt, pero en su esfuerzo por restituir el carácter potenciador y generativo de esta noción (como sugiere su etimología) realiza algunos énfasis y ajustes en los términos:

La relación de autoridad, ni igualitaria ni jerárquica en el sentido estricto de la relación mando/obediencia, implica sin embargo una disimetría característica: reconocen mutuamente la justeza y legitimidad de esa disimetría en la que cada una de ambas partes tiene su lugar establecido "de antemano". (Revault d'Allonnes, 2008, p. 42)

Esta autora busca quitarle el corsé que la figura mando/obediencia le pone a la noción de autoridad, para que tome la forma de una relación olvidada con el paso del tiempo, mayormente vinculada a la palabra auctor: la relación entre "el innovador (o incitador) y quienes colaboran en la empresa y la terminan" (p. 48). El sustantivo agente auctor devuelve la auctoritas a la patria de la fundación. La autoridad es, pues, "el poder de los comienzos" (y así Revault d'Allonnes intitula su ensayo).

Por otro lado, a partir de un análisis fenomenológico Kojève (2006) afirma que la autoridad es una relación social, en tanto requiere al menos dos personas involucradas - nadie es, o encarna o ejerce, autoridad en soledad - que hacen pleno uso de su voluntad y conciencia. Una de las primeras definiciones que ofrece el autor la hace en términos de acción/reacción:

Solo hay autoridad allí donde hay movimiento, cambio, acción (real o al menos posible): sólo se tiene autoridad sobre lo que puede "reaccionar", es decir, cambiar en función de lo que, o de quien, representa la autoridad (la "encarne", la realice, la ejerza). 
Y, evidentemente, la autoridad pertenece a quien hace cambiar y no a quien experimenta el cambio: la autoridad es, en lo esencial, activa y no pasiva. (p. 35)

Desde esta óptica, hay un agente que produce un acto dirigido a un otro (u otros), y ese otro, aun teniendo la posibilidad de oponerse y renunciar se abstiene de hacerlo; es decir, uno manda y el otro obedece consciente y voluntariamente. En este punto Kojève coincide con Arendt en tanto ambos excluyen el uso de la fuerza y colocan como elementos inherentes de esta relación la voluntad, la libertad y el reconocimiento. Kojève dirá que "toda Autoridad es necesariamente una autoridad reconocida; no reconocer a una autoridad es negarla y, por eso, destruirla" (2006, p. 38). En este acto de reconocimiento se sostiene la relación y la autoridad adquiere un carácter legal y legítimo que trasciende el mero derecho: nadie puede encarnar o ejercer la autoridad como un derecho, es decir, por el solo hecho de ocupar un rol jerárquico en un sistema de relaciones. Cualquier derecho a mandar puede ser invalidado con un acto de oposición y negación del reconocimiento por parte de aquel a quien se dirige la orden.

Esta tensión entre el derecho (de quien manda) y el reconocimiento (de quien obedece) nos conduce al problema del origen de la autoridad, el cual es abordado por Ricoeur (2008) en "La paradoja de la autoridad". Allí pone en relación el sustantivo autoridad con el verbo autorizar para distinguir dos polos posibles: la legitimidad de quien manda, su derecho a mandar, y el reconocimiento por parte del subordinado del derecho del superior. Entonces, ¿de dónde viene la autoridad en última instancia? Para avanzar sobre este problema Ricoeur introduce el par credibilidad/confianza (o "dar crédito"): se precisa una cierta confianza para autorizar la autoridad (valga la redundancia); un acto de dar crédito a la credibilidad que del otro lado se ofrece. El derecho, preestablecido, de quien manda no puede garantizar el establecimiento de la relación autorizado/autorizante sin esa cuota de confianza o crédito, la cual siempre es inestable.

Desde una perspectiva psicosocial Sennett (1982) concibe la autoridad como un vínculo emocional (junto con la soledad, la fraternidad y la ritualidad) con consecuencias políticas. Se trata de un tipo de lazo que permite el funcionamiento de la sociedad y sus instituciones, pero que en tanto "emocional" es frágil, móvil e histórico. "El vínculo de autoridad está formado por imágenes de fuerza y debilidad; es la expresión emocional del poder" afirma Sennett (1982, p. 12). De aquí se desprenden algunas consideraciones relevantes para este trabajo: 1) se trata de un vínculo - en sintonía con Kojève, que hablaba en términos de relación social-, pero con un plus sicoafectivo, las emociones; 2) se manifiesta en imágenes, es decir, la experiencia que tengamos con la autoridad estará fundada en "un acto de imaginación" (p. 186), y por ello corresponde más a los asuntos íntimos que a los públicos, aunque en estos últimos tenga sus resonancias; 3) que las imágenes sean de fuerza y debilidad nos lleva a comprender que "es un vínculo entre personas desiguales" (p. 18), una desigualdad que opera en términos de fuerza y poder, y 4) en sintonía 
con esto último, el poder entra en juego en tanto "expresión emocional" pues depende de un cierto proceso de interpretación o significación por parte de los sujetos sobre eso que ocurre en las relaciones de fuerza y control que ellos protagonizan; en este sentido, autoridad y poder no son sinónimos, pero tampoco son ajenos entre sí. Estas ideas abonan significativamente al problema que nos hemos planteado en este escrito, pero no lo simplifican en lo absoluto. De hecho, la preocupación central del autor gira en torno a la relación, siempre tensa, entre autoridad y libertad en las condiciones de sociabilidad que la modernidad impone. Al respecto, Sennett dice:

Nuestro problema se halla en el terreno de lo que es ser libre, y es un problema auténtico. Las formas dominantes de autoridad en nuestras vidas son destructivas; carecen del elemento de protección, y la protección - el amor que sostiene a otros- es una necesidad humana básica, tan básica como la de comer o la sexual. La compasión, la confianza, las seguridades, son cualidades que sería absurdo relacionar con esas figuras de autoridad en el mundo moderno. Y, sin embargo, somos libres: tenemos la libertad para acusar a nuestros amos de que nos faltan esas cualidades. La dificultad está en que el mismo acto de rechazarlos establece vínculos con ellos. (1982, p. 117)

En principio, Sennett califica de "destructivas" a las imágenes de autoridad que la modernidad ha logrado establecer con el desarrollo del capitalismo. Sin embargo, no priva a la autoridad de su necesidad, para fundar vínculos y para que funcione la sociedad, ni de la posibilidad de que asuma formas más "edificantes" (por usar un antagónico) o "fundantes" (para remitirnos al auctor romano). Por otro lado, nos habla de una libertad de la que todos disponemos para enfrentar, rechazar, cuestionar la autoridad, e incluso para acusar a nuestros amos por sus modos de encarnarla. No obstante, dichas reacciones pueden conducir a una mayor atadura del lazo de dependencia que une las partes. Esta es la paradoja que nos ofrece el autor, la cual nombra como "vínculos de rechazo": una imagen de autoridad que, aunque deslegitimada, no pierde su fuerza vincular (en tanto unión o conexión) y vinculante (en el sentido de imposición). En esto se diferencia radicalmente de los autores previamente mencionados, para quienes la expresión "autoridad deslegitimada" solo puede ser un oxímoron. Para Sennett, el problema está en esa paradoja: al observar que las autoridades dominantes son destructivas, ¿qué hace que sigamos atados a ellas, aun pudiendo hacer uso de nuestra inalienable libertad y aun manifestando abiertamente nuestro rechazo?, ¿qué seguridades y certezas nos brindan, en detrimento de nuestra propia libertad, para que el rechazo no se convierta en una auténtica renuncia a su omnipotencia? O mejor, en sus palabras, “'hasta qué punto puede someterse la humanidad a la incertidumbre, a las medias a medias, a la infelicidad, a fin de ser libre?" (1982, p. 127). Este es un problema moral que el autor ubica en las raíces de la civilización occidental. 


\section{¿Qué emancipación?}

La palabra latina emancipare significa "libertar de la potestad paterna, de la tutela o de la servidumbre" (Corominas, 1987, p. 226). Se trata de un movimiento en dirección a una libertad que previamente no se tenía, independientemente de quién sea el agente del movimiento: ser emancipado por otro o emanciparse uno mismo. Pero esta definición no nos aporta más que una sinonimia con la palabra libertad. En 1784 Kant definió el término alemán Mündigkeit (traducido habitualmente como "emancipación") como "la salida del hombre de su condición de menor de edad, de la cual él mismo es culpable. La minoría de edad es la incapacidad de servirse de su propio entendimiento sin la dirección de otro" (Kant, 1994, p. 7). Aquí la noción en cuestión queda ligada a esta capacidad o incapacidad de entendimiento sin la ayuda de un otro, con lo cual se establece una tajante división en el universo humano: los mayores y los menores, los capaces y los incapaces, los autónomos y los dependientes, los sabios y los ignorantes.

En contraposición a esta lógica desigual de Kant, que ha dominado en la pedagogía tradicional, Rancière (2010) va a abogar por un pensamiento de la emancipación basado en un principio igualitario compuesto por dos axiomas:

Primero, la igualdad no es una meta a alcanzar, es un punto de partida, una presuposición, el camino para una posible verificación. En segundo lugar, la inteligencia es una. No hay una inteligencia del maestro y una inteligencia del alumno, una inteligencia del legislador y otra del artesano, etc. Hay una inteligencia que no coincide con ninguna posición en el orden social, que pertenece a todos por ser inteligencia de todos. Emancipación entonces significa la afirmación de esa inteligencia y la verificación del potencial de igualdad de las inteligencias. (p. 133)

Desde esta perspectiva, no existen los "menores" en inteligencia, ni los "inferiores" ni los "incapaces" pues todo ser humano puede lo que pudo otro ser humano. Decir que la inteligencia es una, y por ello indivisible y no jerarquizable, implica que todos podemos lo mismo en tanto seres parlantes y pensantes. El principio igualitario opera como una óptica desde la cual miro al otro: si lo miro como un igual, me dirigiré a él también en condición de igualdad, confiando en que puede decir, pensar y hacer lo mismo que puedo yo o cualquier otro ser humano. Rancière (2010) no duda en afirmar que "la hipótesis de la emancipación es una hipótesis de confianza" (p. 139).

La concepción de ser humano para este autor queda definida por dos términos y es expresada del siguiente modo: "El hombre es una inteligencia al servicio de una voluntad" (Rancière, 2007, p. 73); es decir, la voluntad comanda y pone a trabajar a la inteligencia para perseguir sus fines. Cuando ocurre que dos inteligencias coinciden, eso lleva como nombre embrutecimiento. Los maestros explicadores son los paladines del embrutecimiento, en tanto procuran que los 
estudiantes comprendan los contenidos de una asignatura (aplicando determinados razonamientos de forma gradual) tal cual los comprenden ellos. Lo opuesto al embrutecimiento es la emancipación, que es definida, en estos términos, como "un acto de una inteligencia que no obedece más que a sí misma, aun cuando la voluntad obedece a otra voluntad" (p. 29). Para que un movimiento de orden emancipatorio se produzca es preciso que la inteligencia tome su propio rumbo en el bosque de los símbolos, esto es, que no se subsuma a otra inteligencia: $\mathrm{I}_{1}$ $\neq \mathrm{I}_{2}$. Sin embargo, esta condición no se aplica para la voluntad, que puede o no coincidir con otra voluntad: $\mathrm{V}_{1} \neq \mathrm{V}_{2} \circ \mathrm{V}_{1}=\mathrm{V}_{2}$. Una voluntad que obedece a otra voluntad no es equivalente per se a embrutecimiento.

Por otro lado, Rancière (2007) advierte que nadie es emancipado por otro pues la emancipación es un proceso individual por el cual alguien debe desear pasar. De esta manera, la antiquísima y prestigiosa figura del maestro parece tornarse prescindible, o peor aún, un obstáculo para la emancipación intelectual de los estudiantes. Pero la experiencia misma de Jacotot nos habla de una presencia magisterial frente a un grupo de estudiantes universitarios que, a partir de una consigna sencilla, generó las condiciones para que la emancipación se desplegara. Así, hace su aparición la figura del maestro emancipador: la enseñanza universal encuentra su agente. Entonces, si bien nadie puede ser emancipado por otro, existe la posibilidad de que cualquier individuo se emancipe con un otro que ayude a traccionar su propia voluntad para que no caiga en la distracción o en la pereza y desvíe así su camino. "Se aprende conmigo lo que ignoro", dirá Jacotot (2008, p. 287). El maestro ignorante no explicó ni transmitió nada de su ciencia a los estudiantes de la Universidad de Lovaina; no obstante, su presencia en el salón de clase tuvo lugar bajo la forma "profesor" o "maestro"1.

Entonces, ¿cómo se deviene maestro emancipador?, ¿qué tiene que hacer un maestro para no pecar de embrutecedor - porque no hay otra opción, "quien enseña sin emancipar, embrutece" (Rancière, 2007, p. 33) - ? Si bien fue por azar que Jacotot devino maestro emancipador, su afán por repetir eso que había sucedido en Lovaina lo llevó a consolidar su propio método de enseñanza. Sin embargo, tanto Jacotot como Rancière se ven en la necesidad de realizar algunas aclaraciones con respecto a qué denominan método en la enseñanza universal. El primero dice:

Se ha dado el nombre de método a una cierta sucesión de explicaciones orales, dadas por un maestro instruido a un alumno ignorante. Esta significación de la palabra método, siendo conocida por todo el mundo, no es aplicable a la enseñanza universal, en la que no se explica nada. [...] La enseñanza universal es un método por el cual se enseña lo que se ignora. (Jacotot, 2008, p. 286)

1 Aquí estos sustantivos son tomados como sinónimos, pero sobre el final del trabajo haremos una oportuna y significativa distinción entre ellos. 
Se trata de un modo de enseñar y de aprender que está presente a lo largo de toda la historia de la humanidad y que ha convivido con los métodos explicadores, pero hasta aquel momento nadie lo había usado como un método para instruir a los demás. Luego Jacotot (2008, p. 291) agrega: “El maestro no posee método; él dice: 'hagan'; y el alumno obedece a través de su propio método". De este modo, el énfasis queda puesto en el individuo que aprende, y por ello, más que un método de enseñanza es el método natural, universal, de la mente humana para aprender.

Por su parte, Rancière hace su propia observación sobre el significado del término:

Un "método" no es un conjunto de procedimientos. Es una manera de marchar. A cada paso, es el sentido de la marcha lo que cuenta. Existe en efecto una elección inicial e irreversible entre dos modos de marchar: se va de lo que se ignora a lo que el maestro sabe, o se va de lo que ya se sabe a un nuevo conocimiento; se verifican incapacidades o se verifican capacidades. (2008, p. 17)

La enseñanza universal será, entonces, una manera de marchar que desestima la meta para centrarse en el punto de partida: la igualdad de inteligencias. Asimismo, cabe destacar que en reiteradas ocasiones Rancière $(2007 ; 2008)$ califica la enseñanza universal como un antimétodo con el fin de alejarla del universo de los metodólogos, quienes se aferran al orden progresivo y a las metas a alcanzar.

Haciendo estas salvedades, los autores establecen ciertas sugerencias, indicaciones y principios para la misión emancipatoria, pero todas ellas descansan en una primera condición ineluctable: "Aquel que quiere emancipar al otro debe ser él mismo emancipado", afirma Jacotot (2008, p. 279). Es decir, "ser consciente del verdadero poder de la mente humana", en palabras de Rancière (2007, p. 31). Vivir consciente y consecuentemente la igualdad de las inteligencias.

\section{Joseph Jacotot: un maestro ignorante autorizado}

En la Universidad de Lovaina Jacotot logró que los estudiantes aprendieran francés sin tener que explicarles nada, sin tener que poner a trabajar sus propios conocimientos del idioma ni los tradicionales métodos pedagógicos. No obstante, en definitiva algo les había enseñado y una relación de tipo pedagógica allí se había producido. Ahora bien, ¿qué rasgos asumió la relación pedagógica que se estableció entre Jacotot y los estudiantes?, ¿se trató de un vínculo de autoridad?, ¿qué otros sucesos y guiños de su historia contribuyen a pensar el problema planteado? A continuación sostendremos que Jacotot ofició como una figura de autoridad, primero, por el tipo de relación pedagógica que sostuvo con sus estudiantes, y segundo, porque en su camino produjo libros, fundó un método de enseñanza, creó un periódico y cosechó discípulos. 


\section{Relación pedagógica: disimetría, voluntad y confianza}

Jacotot se presentó en aquél salón de clases como profesor de francés. Independientemente de su formación profesional y de lo mucho o poco que sabía de francés, la posición que allí asumió frente a los estudiantes fue la de un profesor universitario: se paró frente a ellos y con la colaboración de un intérprete les pidió que aprendieran el texto francés de Telémaco con la ayuda de la traducción. Los estudiantes allí presentes escucharon y obedecieron. Pero, ¿qué hizo que obedecieran?, ¿qué los llevó a cumplir con el pedido de un desconocido? En principio diremos que hay un deseo de por medio, el de aprender francés, que puso en marcha sus voluntades bajo la forma de la obediencia: si para aprender francés es necesario leer la edición bilingüe de Telémaco - de modo que se pongan en relación palabras, expresiones y oraciones escritas en uno y otro idioma-, entonces, ¡hagámoslo! Pero con esta sola lectura no se resuelven los interrogantes: ¿Acaso no podrían haber tomado la iniciativa ellos mismos: agarrar un libro bilingüe y comenzar el desciframiento de signos?, ¿o acaso no sabían que podían aprender solos, sin la mediación de un maestro explicador?, ¿es preciso que alguien les enseñe lo que pueden hacer, dándoles un impulso inicial?, ¿qué autoriza a ese alguien, ese otro incitador o iniciador, a pararse delante de un grupo de personas y darles una tarea para hacer, una consigna para resolver?

Remontándonos a aquella situación, y aunque no contemos con mayores detalles en los relatos de Jacotot y Rancière, se nos presenta una imagen bastante nítida de los hechos y su escenario. Esta imagen delata la disimetría que operó en la relación Jacotot-estudiantes tanto en un sentido material como relacional. La materialidad del salón de clases - es decir, el ordenamiento de los cuerpos que este habilita -, sobre todo en aquella época, nos brinda un paisaje conocido: un profesor parado sobre una tarima dirigiéndose a un grupo de estudiantes que se ubican unos escalones más abajo, sentados en sus respectivos pupitres y atentos a las palabras del primero. No hay simetría allí, la disposición de los cuerpos en el salón de clase es muy gráfica al respecto, y dos roles quedan bien definidos: profesor y estudiantes. Pero esta aproximación meramente topográfica no nos dice mucho sobre el tema en cuestión y puede pecar de simplista. Lo que sí resulta relevante ante esta imaginada disimetría material es cómo se habitan esos lugares diferenciados, cómo se asumen los roles institucionalmente preestablecidos, o mejor, de qué modo establecen efectivamente la relación pedagógica los sujetos involucrados en un escenario tal. Atendiendo a esto vemos que la disimetría persevera, en tanto se recrea en un modo de relación: Jacotot, en tanto profesor universitario, imparte una consigna a los estudiantes y estos obedecen voluntariamente. Probablemente no haya otra forma de pensar la relación pedagógica que no sea a partir de una cierta disimetría entre las partes. Este desnivel que distingue posiciones en el contexto educativo puede tambalear, puede pretender horizontalidad, puede incluso revertirse, pero siempre habrá alguien que haga uso de su voz para expresarse, comunicar o pedir algo y alguien que autorice dichas palabras, las reciba con atención y haga algo con ellas. ¿Niega esto el principio igualitario de la enseñanza universal, y por ende 
también la posibilidad de emancipación?, ¿se trata acaso de "esa pasión o esa ficción de desigualdad que desarrolla sus consecuencias" (Rancière, 2007, p. 106)? Aquí cabe hacer una oportuna salvedad: la igualdad que anuncian Jacotot y Rancière como principio universal es una igualdad de inteligencias, pero más precisamente, de potencial o capacidad intelectual:

No hay dos tipos de mente. La desigualdad existe en el orden de las manifestaciones de la inteligencia, para descubrir y combinar nuevas relaciones, pero no hay jerarquía de capacidades intelectuales. La toma de conciencia de esta igualdad de naturaleza se llama emancipación y es lo que abre el camino para cualquier aventura en el país del saber. (Rancière, 2007, p. 44)

Para comprender la disimetría de la relación pedagógica en el terreno de la igualdad y la emancipación es preciso distinguir entre la capacidad de inteligencia y su manifestación, así como también entre inteligencia y voluntad. La emancipación pone una única condición referida a las manifestaciones de la inteligencia: $I_{1} \neq I_{2}$. Las voluntades en juego pueden coincidir o no: $V_{1} \neq V_{2} 0$ $V_{1}=V_{2}$. De este modo, en una situación entre individuos del tipo $I_{1} \neq I_{2} y_{1} \neq V_{2^{\prime}}$ donde 2 antepone una diferencia o una oposición a la voluntad y la inteligencia de 1 , puede acontecer allí un movimiento emancipatorio de 2, el aprendizaje autónomo sigue esta lógica, pero lo que definitivamente se desvanece es la posibilidad de un acto educativo: no habría allí una relación pedagógica entre 1 y 2 . Y si en cambio la relación toma la forma $I_{1} \neq I_{2}$ y $V_{1}=V_{2}$, donde 2 somete su voluntad a la voluntad de 1 sin perder autonomía sobre su inteligencia, quedan establecidas las condiciones mínimas para que un vínculo de autoridad se produzca en el seno de una enseñanza emancipatoria.

Se trata, entonces, de una obediencia voluntaria que no compromete el camino autónomo de la inteligencia. Pero, ¿en qué se funda dicha obediencia?, ¿es por el solo hecho, o derecho, de ser profesor (encarnar dicho rol) que los estudiantes se someten a su voluntad? Hemos visto ya con Ricoeur (2008) que la pregunta por el origen de la autoridad, y por lo que en definitiva sostiene el vínculo, nos conduce a una paradoja que se dirime entre dos polos: el derecho de quien manda y el reconocimiento por parte del subordinado de ese derecho. En este sentido, con el mero posicionamiento de Jacotot como profesor legítimamente ubicado allí no basta para que un vínculo de autoridad se produzca. Es necesario que haga su aparición el reconocimiento de aquellos a quienes dirige su palabra, y más específicamente, su pedido. Sabemos por el hecho de que los estudiantes llevaron a cabo la tarea solicitada que tal reconocimiento fue otorgado. La obediencia voluntaria sería, entonces, la materialización del reconocimiento; pero esta afirmación no explica el hecho. Es la confianza el componente que puede ayudarnos a resolver el enigma del origen. Los estudiantes de Lovaina confían en que lo que diga o haga el nuevo profesor será con fines educativos y será lo suficientemente apropiado para que favorezca el aprendizaje del idioma francés. Sin esta confianza mínima, no hay relación pedagógica posible. 
Cornu (1999) no duda en afirmar que la confianza, en tanto hipótesis sobre la conducta futura del otro, es una actitud constitutiva de la relación pedagógica. En la experiencia de Jacotot sobre todo se trata de una confianza mutua: por un lado, los estudiantes confían en la presencia y la palabra del profesor que se para frente a ellos y la reciben como algo genuino, algo digno de su silencio y su atención; por otro lado, el profesor confía en que los estudiantes pueden aprender - pensar, decir y hacer- al igual que él y que cualquier ser humano, y a partir de esta suposición les exige el cumplimiento de una tarea. Siguiendo las pistas de Ricoeur (2008) el fenómeno de la autoridad incluye tanto la credibilidad, con la que se hace presente un individuo en una situación determinada, como la confianza, ese acto de dar crédito que le otorga un segundo individuo a la credibilidad del primero. La credibilidad la trae consigo el maestro por el hecho de ocupar una posición definida de antemano, pero el vínculo de autoridad no se cierra con este solo hecho pues resulta imprescindible que el estudiante autorice al primero y al lugar que este ocupa. La confianza, en este sentido, aparece como una actitud o gesto que el subordinado dirige al superior y con el cual reconoce su superioridad. Para que haya autoridad con esta condición basta; pero no así para que la autoridad tenga fuerza emancipatoria. Para que esto último ocurra la confianza deberá ser mutua, esto es, que prime la hipótesis de igualdad de inteligencias entre los individuos involucrados.

\section{Vida y obra: autoría, grandeza y discipulazgo}

Otros dos hechos de la historia de Jacotot permiten considerarlo como una autoridad: en primer lugar, que fue el autor de cinco libros ${ }^{2}$ y el fundador de un método de enseñanza y de la filosofía panecástica; en segundo lugar, como efecto de lo anterior, el hecho de que a partir de sus enseñanzas no solo emergieron estudiantes emancipados, sino también discípulos.

La palabra latina auctor, como lo vimos con Revault d'Allonnes (2008), nos conduce al terreno de la fundación, al "poder de los comienzos". El semiólogo Emile Benveniste, en su Vocabulario de las instituciones indoeuropeas, dice: "Se califica de auctor, en todos los dominios, a aquel que 'promueve', que toma una iniciativa, que es el primero en producir alguna actividad, aquel que funda, aquel que garantiza y, finalmente, al 'autor'"' (1983, p. 327). La auctoritas toma su forma de las funciones semánticas de aquella palabra:

Es el acto de producción, o la calidad que reviste el alto magistrado, o la validez de un testimonio o el poder de iniciativa [...] Toda palabra pronunciada con la autoridad determina un cambio en el mundo, crea algo; esta cualidad misteriosa es lo que augeo expresa, el poder que hace surgir las plantas, que da existencia a una ley. (p. 327)

2 Entre sus obras figuran Enseignement universel, langue maternelle (1823), Musique, dessin et peinture (1824), Mathématiques (1827), Langues étrangères (1828) y Droit et philosophie panécastiques (1837). De todas ellas solo la primera se encuentra traducida al español. 
En esta ocasión la autoridad toma una notable distancia de la relación mando/ obediencia que veíamos bajo el subtítulo anterior. Aquí la auctoritas se enlaza a la potencia productora del auctor, al misterioso acto de creación.

Ante la experiencia vivida en Lovaina, Jacotot no se contentó con los logros "pedagógicos" obtenidos y se propuso repetir eso que había ocurrido una vez por azar. Su inquietud lo impulsó a continuar la aventura intelectual y a reflexionar sobre los hechos. Es decir, Jacotot trabajó, insistió, no se distrajo, no sucumbió a la pereza. Y más aún, el camino que tomó y las certezas que iba recolectando en su andar se oponían a una fuerte tradición pedagógica que imperaba en la época, por lo que recibió severas acusaciones en su contra. No obstante, autorizó su voz y confrontó la casta de pedagogos que defendían el viejo método. Sus ideas y controversias fueron plasmadas en obras escritas que perduraron en el tiempo. No enfatizamos estos esfuerzos para hacer de este personaje una figura heroica, sino para no perder de vista el contexto en el cual estaba inserto y para acentuar el carácter disruptor de sus ideas y su obra. Un hombre que se animó - se autorizó- a pensar diferente, y no solo eso, sino que además se hizo escuchar: anunció y difundió la "buena nueva" y llegó a crear un nuevo método de enseñanza (enseñanza universal), una escuela filosófica (filosofía panecástica) orientada por el principio igualitario, un periódico (Periódico de filosofía panecástica) donde analizaba y comunicaba diversas manifestaciones intelectuales y las producciones escritas que tomaron forma de libros. Estos datos nos permiten comprender determinadas actos de creación del auctor Jacotot en términos de actos de resistencia. Para Deleuze (2012) el acto de creación hace su aparición a partir de una necesidad o situación problemática en la que una persona se encuentra, y se manifiesta como la instauración de una diferencia frente a la repetición. Esta lectura subraya la cualidad auctoritas en Jacotot, quien en su paso por este mundo sembró (entiéndase: creó, fundó, hizo nacer, dio comienzo, etc.) y diseminó (entiéndase: acrecentó, promovió, aumentó, etc.) su enseñanza universal.

A todo esto se le suma el hecho de que Jacotot tuvo sus seguidores o discípulos, quienes a su vez crearon escuelas, sociedades y periódicos en su nombre. ¿Se puede decir que él creó a sus discípulos? Por cierto no, porque al igual que los procesos de aprendizaje, de formación y de emancipación el discipulazgo es un asunto personal. Se trató, entonces, de distintos individuos que se acercaron a él, escucharon o leyeron sus palabras, confiaron en estas y lo siguieron. Y seguramente esto sucedió sin que mediase la voluntad de Jacotot para generar adeptos. Es más, si así lo hubiese querido, si se hubiese propuesto tener discípulos, probablemente hubiese fracasado en la tarea, pues el hecho de que una persona siga a otra por propia voluntad se corresponde con esos estados que Jon Elster llama "subproductos":

La paradoja básica de estos estados es que, aunque son lo que más importa, nos eluden en cuanto los convertimos en la meta inmediata de nuestra actividad. El único modo de generarlos consiste en no apuntar a ellos, sino perseguir otras metas y esperar que se 
produzcan "por sí mismos" [...] El sujeto nunca puede dominar y manipular plenamente el modo en que provoca la transferencia en los otros; siempre hay algo "mágico". (Žižek, 2000, p. 132)

La autoridad es uno de estos estados (junto con el amor, el reconocimiento, el respeto y la dignidad). Jacotot hizo su propio camino y en su andar se fueron sumando otros caminantes, personas que por diversos motivos, siempre personales, dieron crédito a sus palabras y actos, lo autorizaron y por ello lo siguieron. Seguidores fieles y seguidores ocasionales, discípulos férreos y discípulos blandos, quienes repetían sus palabras con exactitud y quienes hacían algo distinto con ellas. Ante los variados destinos que tomaban sus enseñanzas en manos de los discípulos Jacotot se vio en la necesidad de clasificarlos según su proceder con respecto a los principios de la enseñanza universal:

Los dividió en dos clases, discípulos enseñadores o explicadores del "método Jacotot" que buscaban conducir a los alumnos de la enseñanza universal a la emancipación intelectual y discípulos emancipadores, que solo instruían bajo la condición previa de la emancipación o incluso que no enseñaban nada y se conformaban con emancipar a los padres de familia, mostrándoles cómo enseñar a sus hijos lo que ellos ignoran. (Rancière, 2007, pp. 168-169)

Aquí la autoridad se hace manifiesta en su doble modalidad: bajo su forma mando/obediencia y como el poder de los comienzos. La primera, como ya sabemos, no tiene que ver con tiranía alguna ni con la obediencia a ciegas, sino con una relación del tipo credibilidad/confianza, y en este caso particular puede ser entendida como una relación entre un iniciador o incitador y sus seguidores o colaboradores, como lo sugería Revault d'Allonnes (2008). De este modo, la primera y la segunda modalidad de manifestación de la auctoritas, encuentran un punto de encuentro. Si bien Jacotot no creó a sus discípulos por propia voluntad, sí fue a partir de su presencia (su propio caminar, su búsqueda incesante, sus enseñanzas y sus obras) que el discipulazgo hizo su aparición. Y aquí la ecuación se simplifica: sin maestro no hay discípulos.

Por otro lado, el acto de clasificar a sus discípulos tiene un tinte oscuro que lo acerca a una especie de castigo para quienes yerran el camino o no son lo suficientemente fieles a sus principios. Claramente los discípulos relegados a la nominación enseñadores o explicadores, si bien compartían el propósito de la emancipación intelectual, se hallaban más del lado del embrutecimiento, por cuanto Jacotot no los consideraba a ellos mismos emancipados. ¿Será este el precio a pagar por escamotear fidelidad o será simplemente un efecto circunstancial de la fidelidad de Jacotot para con sus propias ideas y principios?

Consideramos que las palabras discípulo y maestro en la obra de Rancière, no fueron escogidas arbitrariamente, y por ello creemos oportuno hacer un breve rastreo semántico de aquellas. ¿Qué es un discípulo? La primera acepción del diccionario de la Real Academia Española (2017), dice: "Persona que aprende una doctrina, ciencia o arte bajo la dirección de un maestro". Lo que resuena 
fuertemente de esta definición es la condición "bajo la dirección de un maestro", que nos remite de inmediato a un vínculo disimétrico en el cual el maestro oficia como una autoridad ante el sujeto que aprende. La segunda acepción reza del siguiente modo: "Persona que sigue la opinión de una escuela, aun cuando viva en tiempos muy posteriores a los maestros que la establecieron". Lo novedoso aquí es la dimensión temporal: el discipulazgo como una actitud que ofrece resistencia al paso del tiempo hace perdurar la idea u opinión de un maestro que puede ya no estar. También podríamos decir que discípulo es aquel que dota de autoridad a una idea o a una persona y por ello la sigue y la defiende de los embates del tiempo y del olvido, así como de ocasionales atacantes. La tesis central de Revault d'Allonnes (2008) es que la autoridad tiene que ver con el tiempo, es decir, con la generatividad, la duración, la continuidad, la perduración: "El carácter temporal de la autoridad - más precisamente, la generatividad - hace de ella una dimensión insoslayable del lazo social: asegura la continuidad de las generaciones, la transmisión, la filiación" (p. 15). En la historia que venimos trabajando son los discípulos - más o menos fieles, más o menos obedientes - los que hacen de Jacotot una figura de autoridad en su tiempo y en tiempos posteriores. El mismo Rancière, revitalizando su historia y sus obras sobre finales del siglo XX, podría ser visto como un acérrimo discípulo de aquel en la actualidad. Ante esta idea recobra fuerza la noción de reconocimiento, ese gesto que coloca y mantiene a una persona en posición de autoridad. Asimismo, se acentúa el carácter generativo o creador del auctor, no solo por la producción de libros, sino también por el legado que dejó con sus discípulos. Se da aquí una suerte de dialéctica en la que maestro y discípulo no son uno sin el otro, y la cuestión del origen (¿quién fue primero?) solo nos conduce a un callejón sin salida.

En relación con esto último, y porque la autoridad es un vínculo (Sennett, 1982) o una relación social (Kojève, 2006), resulta preciso avanzar con la próxima pregunta: ¿Qué es un maestro? A pesar de sus numerosos sinónimos esta palabra cobija su propio secreto. La palabra latina magister significa "el que enseña" (Corominas, 1987, p. 373), o "el que está más experimentado en una actividad cualquiera y por eso dirige y ordena" (Anders, 2016). Esta última acepción pone el acento en el derecho a mandar presente en la definición de autoridad trabajada por Ricoeur (2008). El hecho de ser "más experimentado" que otros adjudica al maestro un derecho que lo ubica por sobre los otros, a quienes puede dirigir y ordenar. Pero un sujeto deviene maestro siempre y cuando haya alguien que se posicione ante él como estudiante o discípulo y reconozca su derecho a hablar, dirigir y ordenar. Un maestro desautorizado no puede enseñar, ni dirigir ni ordenar a nadie, y por ello no sería merecedor de tal nombre. Pero hay algo más en esta palabra que evidencia su ligazón con la noción de autoridad, el plus de la grandeza. Duschatzky (2008) nos advierte de esta cualidad: "Maestro viene de mag, raíz de magno, grande, porque en lo antiguo el maestro era el grande de la sociedad, el dictador, de donde viene la voz magistrado, que no es otra cosa que el maestro del foro (...) el maestro es autoridad" (pp. 130-131). De este modo, la palabra maestro queda diferenciada de otras semejantes, como profesor, instructor, preceptor y mentor. Solo "el que enseña" merece el estatuto de 
autoridad. Sin embargo, Duschatzky nos habla de la relación maestro/discípulo desde una mirada que le sustrae la potencia emancipatoria. Desde la mirada del discípulo el maestro se hace presente como una figura de grandeza: los atributos positivos de su persona se hallan exacerbados ante los ojos de quien lo observa con fascinación. Admiración, idealización y fascinación son palabras que usa la autora para describir la mirada del discípulo y que aluden a la metáfora del faro para hacer gráfica la imagen de autoridad del maestro: "Pareciera que el maestro es investido de la posibilidad de iluminar, de aclarar, de poner luz sobre lo que no está claro: faros que iluminan, que ayudan a no perderse en el camino" (pp. 98-99). El maestro emana un brillo que produce una fuerza de atracción. El problema del faro con respecto a la emancipación es doble: por un lado, su poder lumínico puede encandilar o enceguecer los ojos de quien ose mirarlo de frente; por otro, su semblante, su grandeza, hace que quien se ubique a su lado - a sus pies - sienta el peso de su sombra. Ya Sennett (1982) nos alertaba sobre esto último, al hablar de la autoridad de la persona autónoma:

Una persona bien educada y segura de sí misma puede cuidarse [a] sí misma, es independiente, se distingue de la multitud; todas esas imágenes se expresan en el modismo idiomático de decir que esa gente tiene "clase". Son como faros. En cambio, las imágenes de quienes se hallan en la masa son de personas cuyos caracteres son tan poco notables y están tan subdesarrollados que no despiertan ningún interés. Se hallan en la sombra. (p. 92)

Esta imagen de autoridad que se ha consolidado en el mundo moderno es destructiva: tiene una fuerza basada en la indiferencia, que intima a los demás y produce coerción a través del sentimiento de vergüenza. Son personas que brillan por sí mismas imponiéndose como un modelo a seguir (¿acaso la autonomía en el mundo moderno no oficia como un valor?) o que iluminan - señalan, indican - un posible camino a seguir que antes permanecía en la oscuridad y que no éramos capaces de ver por nuestra cuenta. Al mismo tiempo, arrojan la pesada sombra de su grandeza a quienes están debajo, con lo que los hacen ver minúsculos, inferiores, en otras palabras, despreciables. Desprecio es lo que se recibe de estas personas porque pueden mucho sin depender de nadie. Básicamente no nos necesitan. Para Sennett el respeto y el reconocimiento son los actos que desafían la invisibilización y la vergüenza que producen las personas autónomas sobre los subordinados.

¿Era Jacotot una persona autónoma? No hay forma de que sepamos esto, y tampoco sería conducente para comprender el fenómeno del discipulazgo en la historia de Jacotot. Para avanzar será preciso desplazar el foco del maestro a los discípulos. Tanto desde la mirada fenomenológica de Kojève como desde la perspectiva psicosocial de Sennett la relación o vínculo de autoridad se sostiene sobre todo por la posición que asuma el subordinado. Este es quien involucra su voluntad (Kojève) o su imaginación (Sennett) para que una persona determinada ocupe el lugar de autoridad. Sennett (1982) afirma que la autoridad nace de un acto de imaginación del subordinado. La autoridad no es una cosa, sino tan solo una imagen de fuerza que una persona se fabrica de otra persona. 
La sola palabra maestro, usada para remitirse a un filósofo y profesor universitario, carga con el halo de grandeza. La expresión “¡Es un maestro!” (habitualmente con tono exclamativo) es un ejemplo del alcance de esta palabra pues no se limita al ámbito educativo, sino que adquiere un significado más amplio, que remite a una cierta audacia, superioridad o grandeza. De hecho, la expresión “¡Es un grande!" suele usarse como equivalente en nuestro idioma. Con las palabras profesor, docente e instructor no ocurre lo mismo, en lo absoluto. Por ello, no resulta casual que Jacotot haya sido nombrado por Rancière "el maestro ignorante" cuando este último ha recreado su obra en torno a la figura del primero.

Las palabras grandeza y superioridad, utilizadas para calificar a una persona, no están por fuera del léxico de Jacotot. En Enseñanza universal. Lengua materna, al referirse a la admiración que a él le provocan los "grandes hombres", dice:

Lo que yo admiro en los grandes hombres es la potencia de la inteligencia humana [...]. El sol me deslumbra con sus rayos; pero no es en él que me gusta pensar cuando lo veo. La sociedad produce esos soles cuando le place, ella los extingue a su antojo. El hombre que no escuchara más que la razón sería grande sólo por eso; él no tendría la pasión de brillar que hace llevar a cabo cosas tan grandes: tendría el sentimiento de su dignidad. [...] Aquel del que hablo sería superior a nosotros por la voluntad; pero seguiría siendo nuestro igual por la inteligencia. (Jacotot, 2008, p. 233)

En esta cita la grandeza y la superioridad de una persona quedan definidas por la voluntad que esta ponga en juego y por los resultados intelectuales que dicha voluntad provoque. El carácter diferencial que adquieren los grandes hombres concierne a las manifestaciones de la inteligencia, producto de una voluntad puesta en acción, y no al potencial intelectual, que es uno e igual en todos. El sol es utilizado aquí como una metáfora para ilustrar la admiración hacia esos grandes hombres, y aporta algo nuevo a los planteos de Duschatzky y Sennett cuando hacían referencia al faro. En este caso el deslumbramiento que provoca el sol con sus rayos, lejos de provocar ceguera, idealización, embrutecimiento, etc., puede ser una incitación para pensar en algo más que el sol dejando que la inteligencia tome su propio rumbo. En este sentido, la autoridad que Jacotot reconoce en estos hombres no niega el principio de igualdad. Es más, el hecho de ver a estos grandes hombres como iguales puede resultar una incitación para emprender una aventura intelectual.

Cuando una autoridad, lejos de impulsarnos o incitarnos, se torna opresiva, embrutecedora, lo que resulta oportuno es examinar minuciosamente la imagen de fuerza que de ella hemos creado. Como sugiere Sennett (1982), para liberarnos de los influjos de la autoridad hay que quitar el velo de omnipotencia que la reviste. En el caso que nos compete, si al maestro Jacotot no se le rasga el pesado velo de grandeza, probablemente los discípulos permanezcan como meros seguidores o repetidores de su doctrina. Quizá los discípulos verdaderamente emancipados sean aquellos que tomaron considerable distancia de su maestro y se aventuraron a iniciar su propio camino. El mismo Rancière puede ser un 
ejemplo de ello en tanto toma la vida y la obra de Jacotot para dar respuesta a sus propias preocupaciones, que tienen que ver más con el campo políticofilosófico que con el educativo.

Nietzsche (2003) hace hablar a su Zaratustra del siguiente modo:

Se recompensa mal a un maestro si se permanece siempre discípulo. ¿Y por qué no vais a deshojar vosotros mi corona?

Vosotros me veneráis: pero ¿qué ocurrirá si un día vuestra veneración se derrumba? ¡Cuidad de que no os aplaste una estatua! [...]

Ahora os ordeno que me perdáis a mí y que os encontréis a vosotros; y sólo cuando todos hayáis renegado de mí volveré entre vosotros. (pp. 126-127)

Al parecer nunca es nítido el límite que separa la libertad de la sumisión y la emancipación del embrutecimiento. Si el discípulo vuelve obcecada e incondicional su fidelidad al maestro, corre el riesgo de ser aplastado por la estatua o ensombrecido por el faro que él mismo ha edificado. Finalmente, el fenómeno del discipulazgo depende menos del maestro que de los discípulos, quienes ven en el primero un refugio ante las inclemencias de las incertidumbres, un faro que orienta en la tormenta, un horizonte para encaminar el rumbo o, en el mejor de los casos, una fuente para renovar fuerzas y seguir caminando.

\section{A modo de cierre}

Autoridad y emancipación, dos nociones que en principio parecían oponerse con rudeza: a lo largo del presente texto hemos logrado aproximarnos a sus intersecciones. También nos hemos topado con paradojas que uno u otro término traían consigo, sobre todo cuando son ubicados en el terreno educativo. Rancière nos advertía al inicio que son justamente las paradojas las que le dan sentido al acto de enseñar, y estas han sido un paso obligado en este recorrido.

La experiencia de Jacotot nos permitió dilucidar algunos aspectos del problema planteado. Teniendo en cuenta tanto la relación pedagógica que entabló con los estudiantes de Lovaina como algunos datos de su vida, sus obras y el fenómeno del discipulazgo que se generó a su alrededor, pudimos ver cómo en su figura confluían distintas formas de concebir la autoridad: desde la ceñida relación mando/obediencia hasta el "poder de los comienzos" del auctor. El maestro ignorante ocupó un lugar de autoridad desde el cual no solo enseñaba francés o divulgaba su enseñanza universal, sino que también promovía movimientos emancipatorios de estudiantes y discípulos. Disimetría, voluntad, confianza y reconocimiento fueron algunos elementos hallados en el vínculo de autoridad que Jacotot entabló con sus estudiantes. Pero las paradojas del acto de enseñar no se demoraron en reaparecer, y al detenernos en la relación maestro/discípulos 
la noción de emancipación se volvió esquiva en algún sentido con respecto al vínculo de autoridad que allí se esbozaba.

Ahora bien, el hecho de que las nociones de autoridad (auctoritas) y autor (auctor) -íntimamente emparentadas, pero que han habilitado recorridos semánticos diferenciados - hayan confluido en una persona (Jacotot en este caso) nos permite desplegar nuevas líneas de indagación sobre autoridad y emancipación. En primer lugar, cabría profundizar en torno a la variabilidad y la fijeza del fenómeno de la autoridad, es decir, la relación entre las diversas figuras que admite su manifestación y los mecanismos intrínsecos que identifican este fenómeno y lo diferencian de otros similares. Creemos que el concepto de reconocimiento resulta clave para este recorrido. En segundo lugar, podríamos preguntarnos qué lugar ocupa la autoconfianza, la autoafirmación de las propias capacidades o una cierta auto-autorización en el acto de creación, en el devenir auctor. Probablemente este sea uno de los enigmas que atesoran las personas que encarnan la autoridad, una cierta seguridad sobre ellos mismos que favorece la producción de vínculos. Pero la exacerbación de la autoconfianza o auto-autorización puede conducirnos a la imagen de autoridad de la persona autónoma descrita por Sennett, un tipo de autoridad que basa su fuerza en la indiferencia y resulta destructiva para quienes se hallan bajo su sombra. Por otro lado, ¿qué es de la vida de una persona que no logra autorizarse, aunque sea por momentos, aunque sea tímidamente? Nos hallamos aquí, entonces, ante un problema que gira alrededor de los procesos de subjetivación: tanto la excesiva autoconfianza como su menoscabo nos alejan de lo que hemos esbozado como autoridad emancipatoria. Finalmente, cabría explorar con mayor detenimiento sobre otros posibles alcances, políticos y pedagógicos, de los vínculos de autoridad en los que conviven la relación mando/obediencia y la generatividad del auctor. Esto supondría hallar nuevos vínculos y situaciones, que trasciendan lo trabajado en este artículo y permitan encaminarnos hacia una teorización más precisa y potente de lo que aquí hemos denominado autoridad emancipatoria.

\section{$\mathbf{R}_{\text {eferencias }}$}

Anders, V. (2016). Maestro. En Diccionario etimológico español en línea. Recuperado de http://etimologias.dechile.net/?maestro

Arendt, H. (1996). ¿Qué es la autoridad? En Entre pasado y futuro. Ocho ejercicios sobre la reflexión política (pp. 101-125). Barcelona: Península.

Benveniste, E. (1983). Vocabulario de las instituciones indoeuropeas. Madrid: Taurus.

Cornu, L. (1999). La confianza en las relaciones pedagógicas. En G. Frigerio, M. Poggi y D. Korinfeld (comps.), Construyendo un saber sobre el interior de la escuela. Buenos Aires: Noveduc. 
Corominas, J. (1987). Breve diccionario etimológico de la lengua castellana. Madrid: Gredos.

Deleuze, G. (2012). ¿Qué es el acto de creación? Revista Fermentario, 6, 1-16. Recuperado de http://www.fermentario.fhuce.edu.uy

Duschatzky, L. (2008). Una cita con los maestros. Los enigmas del encuentro con discípulos y aprendices. Buenos Aires: Miño y Dávila.

Jacotot, J. (2008). Enseñanza universal. Lengua materna. Buenos Aires: Cactus.

Kant, I. (1994). Respuesta a la pregunta: ¿Qué es la Ilustración? Revista Colombiana de Psicología, 3, 7-10. Recuperado de https://goo.gl/ZJW1Ms

Kojève, A. (2006). La noción de autoridad. Buenos Aires: Nueva Visión.

Nietzsche, F. W. (2003). Así habló Zaratustra. Madrid: Alianza.

Rancière, J. (2007). El maestro ignorante. Buenos Aires: Libros del Zorzal.

Rancière, J. (2008). Prólogo: la lengua de la emancipación. En J. Jacotot, Enseñanza universal. Lengua materna (pp. 11-21). Buenos Aires: Cactus.

Rancière, J. (2010). ¿Comunistas sin comunismo? En Momentos políticos (pp. 131-148). Buenos Aires: Capital Intelectual.

Real Academia Española (2017). Discípulo. En Diccionario de la lengua española. Recuperado de http://dle.rae.es/?id=DsLLpKP

Revault d'Allonne, M. (2008). El poder de los comienzos. Ensayo sobre la autoridad. Buenos Aires: Amorrortu.

Ricoeur, P. (2008). La paradoja de la autoridad. En Lo justo 2 (pp. 87-100). Madrid: Trotta.

Sennett, R. (1982). La autoridad. Barcelona: Anagrama.

Žižek, S. (2000). Mirando al sesgo. Una introducción a Jacques Lacan a través de la cultura popular. Buenos Aires: Paidós.

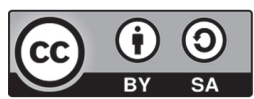

